\title{
P. vivax malaria presenting as shock an unusual manifestation: Case series
}

\author{
Kashyap A ${ }^{1}$, Aggarwal $A^{2}$, Harit $D^{3}$, Eske GS ${ }^{4}$ \\ ${ }^{1}$ Dr Archana Kashyap*, MD, Senior Resident, ${ }^{2}$ Dr Anju Aggarwal*, MD, MNAMS, FIAP, Associate Professor, ${ }^{3}$ Dr \\ Deepika Harit*, Assistant Professor, ${ }^{4}$ Dr Gunvant Singh Eske, MD, Senior Resident, Safdarjang Hospital \& Vardhaman \\ Mahavir Medical college, New Delhi. *All are affiliated with Department of Pediatrics, University College Of Medical \\ Sciences, and Guru Tegh Bahadur Hospital, Shahdra and Safdarjung Hospital' Delhi,India
}

Address for Correspondence: Dr Archana Kashyap, Email: archana425@gmail.com, A-66/e, street no. 6.A -Block, West vinod nagar, Delhi

\begin{abstract}
Shock as a manifestation of Plasmodium vivax infection is rarely reported. Four children aged $8-12$ years with severe vivax malaria presented with shock. Thrombocytopenia was detected in all cases. There were no bleed from any site. Diagnosis of P. vivax was made by blood smear and rapid diagnostic tests. All patients did not responded to initial fluid boluses and improved on steroid and anti malarial therapy being artesunate combination therapy.
\end{abstract}

Keywords: P vivax Malaria, Shock, Children

\section{Introduction}

P. vivax is most widely distributed human malaria parasite with a risk population of 2.5 million persons[1]. The infection is responsible for benign, uncomplicated disease. Newer reports are now suggestive of severe manifestations of P.vivax malaria. Severe manifestation with P.vivax include cerebral malaria, severe anemia, hepatic dysfunction, jaundice, acute lung injury, acute respiratory distress syndrome, pulmonary edema, shock, splenic rupture, renal failure, severe thrombocytopenia with or without bleeding $[1,2]$. Shock as a manifestation of P. vivax is rarely reported[3,4,5]. We report four children diagnosed as severe P.vivax malaria who presented with shock.

\section{Cases}

All four patients (Case 1, 2, 3, 4) presented with shock (Table 1). Other clinical manifestations are shown in Table 1. One patient (Case 2) had features suggestive of renal involvement i.e oliguria. Duration of fever in the cases ranged from 7 - 10 days. All of them did not have any bleeding manifestation except one (case 3 ) where altered blood in stools was seen for 1 day. Their hemoglobin ranged between $7-10 \mathrm{mg} / \mathrm{dl}$. All patients presented with thrombocytopenia. Two of them had platelet count (case 1,4) less than $50,000 / \mathrm{mm}^{3}$ and two (case 2, 3) had platelet count $\leq 1 \mathrm{lakh} / \mathrm{mm}^{3}$. The total leukocyte count was within normal range. Blood culture was sterile in all cases. S.widal and dengue serology was negative. Kidney function tests were normal. Peripheral blood films demonstrated P.vivax trophozoites. Rapid diagnostic slide test was positive for P. vivax and negative for P. falciparum in all cases. All four patients were treated successfully with artesunate combination therapy. All four patients did not respond to initial fluid boluses. Keeping in view the pathophysiology of vivax malaria and possibility of shock due to cytokine storm steroid were given at initial dose of $3 \mathrm{mg} / \mathrm{kg}$ followed by $1 \mathrm{mg} / \mathrm{kg}$ for $48 \mathrm{hrs}$. Clinical response was observed in next $24 \mathrm{hrs}$. Repeat blood malaria smear after two days showed clearance of parasite in all four cases. They were discharged in clinically stable condition and received primaquine for fourteen days. 
Reviewed: $4^{\text {th }}$ Oct 2015

Author Corrected: $13^{\text {th }}$ Oct 2015

Accepted for Publication: $23^{\text {rd }}$ Oct 2015

Table-1:Clinical profile of patients with P.vivax malaria

\begin{tabular}{|c|c|c|c|c|}
\hline Case no & Age/sex & $\begin{array}{llllllll}\mathbf{S} & \mathbf{y} & \mathbf{m} & \mathbf{p} & \mathbf{t} & \mathbf{0} & \mathbf{m} & \mathbf{s}\end{array}$ & $\mathbf{S}$ & Oth e r f e a t u r e s \\
\hline 1 & $8 \mathrm{y} \mathrm{r} / \mathrm{M}$ & Fever, decreased oral acceptance,vomiting & $\begin{array}{l}\text { Puls e } \mathrm{s} \text { feeble, } \mathrm{shock}, \\
\text { Liver } 3 \mathrm{~cm} \text {, spleen } 1 \mathrm{~cm}\end{array}$ & No seizure/altered sensorium. No meningism \\
\hline 2 & $10 \mathrm{y} \mathrm{r} / \mathrm{F}$ & Fever, pain abdomen, decrease urine output & Shock, pallor, liver $2 \mathrm{~cm}$,spleen $3 \mathrm{~cm}$ & No rash/bleed/jaundice \\
\hline 3 & $12 \mathrm{y} \mathrm{r} / \mathrm{F}$ & Fever, vomiting, abdominal pain, bodyache & Shock, pallor, liver $2 \mathrm{~cm}$,spleen $4 \mathrm{~cm}$ & Ma lena for 1 d a y \\
\hline 4 & $12 \mathrm{y} \mathrm{r} / \mathrm{M}$ & Fever, vomiting, pain abdomen, loose stools & Shock, tachycardia, liver $2 \mathrm{~cm}$,spleen-np & No bleed jaundice/oliguria \\
\hline
\end{tabular}

\section{Discussion}

P. falciparum is the most common species reported to cause severe malaria. Recent evidence suggests that P.vivax infection is responsible for severe malaria including shock, anemia, thrombocytopenia, acute lung injury and ARDS [6,7,8]. Pathogenesis of severe malaria includes sequestration related and non sequestration related complications. The essential pathological feature of severe vivax malaria is sequestration of erythrocytes containing mature parasites in the deep vascular bed (cerebral malaria, renal, hepatic involvement). P. vivax-related coma is also considered to be of systemic metabolic origin, but the exact pathological mechanism is still unknown. Other complications such as severe anemia, disseminated intravascular coagulation and thrombocytopenia are considered to be nonsequestration-related with a multifactorial etiology, e.g. haemolysis, reduced cell deformity of erythrocytes, decreased platelet survival and increased uptake [1,2]. Severe anemia is more likely in P. falciparum than in $\mathrm{P}$. vivax owing to the lower density of $\mathrm{P}$. vivax. However, a greater inflammatory response to a given parasite burden is a feature of $\mathrm{P}$. vivax leading to increased sequestration in the pulmonary vasculature and, hence, more respiratory complications such as ARDS and shock $[2,8]$. Though pathophysiology of shock is not clearly defined, increase capillary permeability and leakage of fluid due to increased inflammatory response may be responsible.

All four patients had features suggestive of shock and confirmed diagnosis of P.vivax malaria. In addition to antimalarial therapy these children required fluid boluses and steroids for treatment of shock which can be explained by the pathogenesis of shock mainly due to release of inflammatory cytokines. Shock due to P.vivax malaria has been reported in adults. Kochar et al[6] in 2009 reported severe malaria 1091 adult patients of which 3 patients were in shock. Song et al[3] reported 2 cases of P.vivax malaria in adults presenting toxic shock syndrome, one as thrombocytopenia, renal failure and pulmonary edema and another as

disseminated intravascular coagulation. These patients were treated with fluid bolus and vasopressors.

Now complications are been reported in children, as reported by Kochar DK et al[9] from Bikaner, India. Among 303 children, P.vivax infections were noted in $33.9 \%$ of children. Severe disease was present in $49.5 \%$ of children; P.vivax mono infection was responsible for $63.1 \%$ of these, hence more than P.falciparum. Srivastava et al[4]conducted study in which 74 children were evaluated, of which 50 cases had $\mathrm{P}$ vivax monoinfection, of these 8 cases presented with shock. malaria was diagnosed in 41/50 cases, with thrombocytopenia being the commonest manifestation. Shock was observed in 8 cases. Tanwar et al [5] reported 13 cases of P.vivax cerebral malaria complications of which one presented as shock.

\section{Conclusion}

Hence we emphasize importance of considering shock as a complication of P.vivax infection even in absence of bleeding. Pathophysiology and guideline for the use of steroids in such cases need to be elucidated further. P.vivax malaria can present in severe and complicated form and should be suspected clinically.

Conflict of interest: None declared.

Funding: Nil, Permission from IRB: Yes

\section{References}

1. Kochar DK, Saxena V, Singh N, Kochar SK, Kumar SV, Das A. Plasmodium vivax malaria. Emerg Infect Dis. 2005 Jan;11(1):132-4.

2. Genton B, D'Acremont V, Rare L, Baea K, Reeder JC, Alpers MP, Müller I. Plasmodium vivax and mixed 
infections are associated with severe malaria in children: a prospective cohort study from Papua New Guinea. PLoS Med. 2008 Jun 17;5(6):e127. doi: 10.1371/journal.pmed.0050127.

3. Song JY, Park CW, Jo YM, Kim JY, Kim JH, Yoon HJ, Kim CH, Lim CS, Cheong HJ, Kim WJ. Two cases of Plasmodium vivax Malaria with the clinical picture resembling toxic shock. Am J Trop Med Hyg. 2007 Oct;77(4):609-11.

4. Srivastava S, Ahmad S, Shirazi N, Kumar VS, Puri P. Retrospective analysis of vivax malaria patients presenting to tertiary referral centre of Uttarakhand . Acta Trop. $2011 ; 117: 82-5$.

5. Tanwar GS, Khatri PC, Sengar GS, Kochar A, Kochar SK, Middha S, Tanwar G, Khatri N, Pakalapati D, Garg S, Das A, Kochar DK. Clinical profiles of 13 children with Plasmodium vivax cerebral malaria. Ann Trop Paediatr. 2011;31(4):351-6. doi: 10.1179/1465328111Y.0000000040.
6. Kochar DK, Das A, Kochar SK, Saxena V, Sirohi P, Garg S, Kochar A, Khatri MP, Gupta V. Severe Plasmodium vivax malaria: a report on serial cases from Bikaner in northwestern India. Am J Trop Med Hyg. 2009 Feb;80(2):194-8.

7. Rogerson SJ, Carter R. Severe vivax malaria: newly recognised or rediscovered. PLoS Med. 2008 Jun 17;5(6):e136. doi: 10.1371/journal.pmed.0050136.

8. Mohan $\mathrm{A}^{1}$, Sharma SK, Bollineni S. Acute lung injury and acute respiratory distress syndrome in malaria. J Vector Borne Dis. 2008 Sep;45(3):179-93.

\section{Kochar DK, Tanwar GS, Khatri PC, Kochar}

SK, Sengar GS, Gupta A, Kochar A, Middha
S, Acharya J, Saxena V, Pakalapati D, Garg S, Das A. Clinical features of children hospitalized with malaria-a study from Bikaner, northwest India. Am J Trop Med Hyg. $2010 \quad$ Nov;83(5):981-9. doi: 10.4269/ajtmh.2010.09-0633.

\section{How to cite this article?}

Kashyap A, Aggarwal A, Harit D, Eske GS. P. vivax malaria presenting as shock an unusual manifestation: Case series. Int J Med Res Rev 2015;3(9):1099-1101. doi: 10.17511/ijmrr.2015.19.200. 